(2) Open Access Full Text Article

REVIEW

\title{
Future prospects in the treatment of erectile dysfunction: focus on avanafil
}

This article was published in the following Dove Press journal:

Drug Design, Development and Therapy

17 October 2011

Number of times this article has been viewed

\author{
Amjad Alwaal \\ Raed Al-Mannie \\ Serge Carrier \\ Division of Urology, McGill University \\ Health Centre, Montreal, Quebec, \\ Canada
}

\begin{abstract}
The treatment of erectile dysfunction (ED) has been revolutionized in the last 15 years with the introduction of type 5 phosphodiesterase (PDE5) inhibitors. Their efficacy, safety, and ease of administration have made them first-line treatment for ED. This article reviews the current therapies available for ED, and the new PDE5 inhibitors that are being investigated. Furthermore, it examines all the current ED treatment options that are in different phases of development (including oral and topical pharmacotherapy, gene therapy, and tissue engineering). A special emphasis is on avanafil, a new PDE5 inhibitor that has been studied extensively in Phase I and II clinical trials and has undergone several Phase III trials. Avanafil is a promising medication for ED due to its favorable pharmacokinetics, safety, and efficacy.
\end{abstract}

Keywords: PDE5, sexual performance, pharmacokinetics

\section{Introduction}

Erectile dysfunction (ED) is defined as the persistent or recurrent inability to achieve or maintain an erection sufficient for satisfactory sexual performance. ${ }^{1}$ It is frequently associated with emotional distress and reduced self-esteem. This emotional distress can have a significant impact on the patient's social or marital life, emphasizing the importance of treating this condition adequately. ${ }^{2}$ The Massachusetts male aging study, conducted from 1987 to 1989 in areas around Boston, was a cross-sectional survey of 1290 men aged 40-70 years that looked at the prevalence of ED. Participants self-reported ED, and the condition was classified into mild, moderate, and severe. It was found that the prevalence of ED increased with age, as prevalence was $40 \%$ at 40 years of age and $70 \%$ at 70 years of age. ${ }^{3}$ Penile erection is caused through vascular pressure changes within the corpora cavernosa. The nitric oxide (NO)/cyclic guanosine monophosphate (cGMP) pathway is the key physiological mediator of erection. During psychogenic, reflexogenic, or nocturnal tumescense, NO is released to cause relaxation of the smooth muscle cells of the trabeculae and arterioles of the corpora cavernosa, thus increasing penile blood flow and resulting in erection. Type 5 phosphodiesterase (PDE5) is the main hydrolyzing enzyme of cGMP, thus causing detumescense. PDE5 inhibitors act through competing with cGMP for the enzyme, making cGMP more available and prolonging erection. ${ }^{4} \mathrm{ED}$ can be the result of organic or psychogenic causes, and often both. Organic causes can be classified based on the cause (diabetic, traumatic), or the neurovascular mechanism of the erectile process (failure of initiation [neurogenic], failure of filling [arterial], and failure of storage [venous]). ${ }^{4,5}$ Since ED can be an early indicator of cardiovascular disease, all patients should undergo a complete medical,
Correspondence: Serge Carrier Department of Urology, Jewish General Hospital, 3755 Côte-Sainte-Catherine Road, Montréal, Québec, Canada H3T IE2

Tel +I 5 I4 842 I23I ext 34356

Email serge.carrier@mcgill.ca 
sexual, and psychosocial history, focused physical examination, and laboratory tests. Certain optional and specialized tests of proven value in select situations can be performed and are left to the clinical judgment of the physician. ${ }^{1}$

The ideal treatment of ED should be: easy to administer, noninvasive, not painful, and highly efficacious, with minimal side effects. ${ }^{6}$ Due to the earlier limited understanding of the basic physiological and biochemical mechanisms involved in erection, early treatment of ED consisted of several psychological and hormonal strategies and the use of penile implants and vacuum devices. However, the later deeper understanding of the erection mechanism has allowed the introduction of intracorporeal injections and the later oral PDE5 inhibitors. The oral PDE5 inhibitors have revolutionized the treatment of ED and have become first-line treatment due to their effectiveness and good safety profile. As we continue to understand the erectile mechanism even further, the need for better treatment options for ED has risen. This is mainly due to the shortcomings of the current oral PDE5 inhibitors, which include their occasional ineffectiveness, their limited spontaneity, and their inability to correct the underlying cause of ED. Therefore, researchers are constantly exploring newer and more effective therapies for ED.

In this review, current available therapies for ED are presented. Several advanced and early ED therapy research efforts that are currently being investigated at different stages of development are described, with a special focus on avanafil and its future role in ED treatment.

The authors of this review searched for English language, original articles published in MEDLINE, focusing on erectile dysfunction, between 1991 and 2011. The search terms used were "erectile dysfunction," "new treatment," "avanafil," and "PDE5 inhibitors." The relevant articles were selected, and their reference lists were searched for further articles.

\section{Current ED therapies}

\section{Type 5 phosphodiesterase inhibitors}

The American Urological Association (AUA) has recommended the use of three PDE5 inhibitors so far (sildenafil, tadalafil, and vardenafil) as first-line therapy for $\mathrm{ED}^{7}$ (Table 1).
Sildenafil (Viagra ${ }^{\circledR}$, Pfizer Inc, New York, NY) is rapidly absorbed from the gut to reach the peak plasma concentration within 1 hour. ${ }^{8,9}$ Its half-life $\left(t_{1 / 2}\right)$ is 3-5 hours, with duration of action up to 12 hours..$^{10}$ The time to peak concentration $\left(\mathrm{T}_{\max }\right)$ is reduced with high fatty meal consumption. It demonstrates some cross-reactivity to PDE6 receptors, which are present in the retinal photoreceptors, resulting in color vision abnormalities in some patients. ${ }^{11,12}$ Vardenafil (Levitra ${ }^{\circledR}$, Bayer, Leverkusen, Germany) is rapidly absorbed and its peak plasma concentration is obtained within an hour, with a median of 0.7 hours. ${ }^{13,14}$ The $_{1 / 2}$ is $4-5$ hours. The $\mathrm{T}_{\max }$ is not affected with moderate fat intake but is slightly reduced with a high fat diet. ${ }^{15}$ Vardenafil demonstrates higher selectivity to PDE5 than the other two PDE5 inhibitors. ${ }^{13,16}$ Tadalafil (Cialis ${ }^{\circledR}$, Eli Lilly, Indianapolis, IN) is also rapidly absorbed to reach a peak plasma concentration within 2 hours. ${ }^{16,17}$ Its $t_{1 / 2}$ is, however, 17 hours, which allows a unique duration of action up to 36 hours. Its $\mathrm{T}_{\max }$ is not affected with fat intake. ${ }^{18}$ Tadalafil has some cross-reactivity with PDE11, which is present in the testes and prostate, but there is no known clinical effect associated with this cross-reactivity. It does cause back pain and myalgia in $6 \%$ of patients however. ${ }^{19} \mathrm{All}$ the available PDE5 inhibitors are associated with headache, flushing, dyspepsia, nasal congestion, and dizziness. ${ }^{20}$ They are all contraindicated with nitrates as they might precipitate severe hypotension. ${ }^{21}$ They can be used with $\alpha$-blockers with caution, as the patient should be on $\alpha$-blocker for some time before introducing PDE5 inhibitor, and they should be spaced for at least 4 hours. ${ }^{22}$ PDE5 inhibitors are not recommended for retinitis pigmentosa and have to be used with caution in diseases with a risk of priapism (eg, leukemia and multiple myeloma). There is currently no epidemiological evidence that nonarteritic anterior ischemic optic neuropathy is associated with the use of PDE5 inhibitors; however, the patient should inform the health professional about a history of loss of vision as this warrants ophthalmologic evaluation. ${ }^{23-25}$

\section{Local therapy}

Currently, intracavernosal injection (ICI) of vasoactive substances is considered second-line therapy for ED when oral pharmacotherapy fails or is inappropriate. Intracavernosal

Table I Comparison of avanafil pharmacokinetics to other available PDE5 inhibitors

\begin{tabular}{lllll}
\hline Parameters & Sildenafil & Vardenafil & Tadalafil & Avanafil \\
\hline Available doses, $\mathrm{mg}$ & $25,50,100$ & $5,10,20$ & $5,10,20$ & $20,50,100$ \\
$\mathrm{~T}_{\max }$, hours & $\mathrm{I}(0.5-2.0)$ & $0.7(0.25-3.00)$ & $2(0.5-6.0)$ & $0.593(0.686-0.555)$ \\
$\mathrm{t}_{1 / 2}$, hours & $3-5$ & $4-5$ & 17.5 & $1.19(1.07-1.23)$ \\
Other possible receptor affinity & PDE6 & PDE6 & PDEII & PDE6 \\
\hline
\end{tabular}


alprostadil (prostaglandin E1) has an efficacy rate of $87 \%,{ }^{26}$ while another intracavernosal bimix therapy (phentolamine plus papaverine) has an efficacy rate of $60 \%,{ }^{27}$ whereas a trimix therapy (phentolamine, papaverine, and alprostadil) has an increased efficacy rate to $92 \% .{ }^{28}$ ICI can be associated with penile fibrosis, penile pain, hematoma, and priapism. $^{29}$

Intraurethral alprostadil (MUSE ${ }^{\mathrm{TM}}$, Vivus, Menlo Park, $\mathrm{CA}$ ) represents another second-line pharmacotherapy for ED. It is less efficacious than intracavernosal alprostadil injection with $60 \%$ or less efficacy rate; however, most patients accept it as an easier method of ED treatment. The most common side effects associated with this treatment are urogenital pain and minor urethral bleeding. ${ }^{30}$

\section{Mechanical devices}

The vacuum erection device (VED) is a cylindrical pump that is placed over the penis. Air is pumped out of the device causing blood to flow into the penis. Once erection is achieved, an occlusive ring is placed at the base of the penis to maintain erection. It has an efficacy of $80 \%-95 \%$, with long-term efficacy at $60 \%$. It is contraindicated in bleeding disorders or in patients on anticoagulation. There have been several side effects associated with VED use, the commonest being penile pain. Other side effects include: pain on ejaculation, retarded ejaculation, petechiae on the penis, skin necrosis, and Peyronie's disease. ${ }^{31}$

Penile prosthesis represents a third-line of treatment when other types of less invasive treatments fail. Efficacy is not an issue, as erection is always achieved, and patient satisfaction reaches more than $80 \%{ }^{32}$ There are two types of penile implants: inflatable and non-inflatable (malleable). The inflatable type is more desired by patients; however, it requires more manual dexterity. The 5 -year survival of the three-piece inflatable type is $90 \%-95 \%$. ${ }^{33}$ The main complications for penile implants are mechanical failure, infection, and erosion. ${ }^{32}$

\section{Future treatment of ED}

\section{Pharmacotherapy}

Udenafil is a newer PDE5 inhibitor that has a similar affinity to PDE5 as sildenafil. In a multicenter, double-blind, placebo-controlled, fixed-dose, parallel-group Phase III trial done in Korea, udenafil was found to be an effective and well tolerated therapy for ED. ${ }^{34}$ Udenafil is currently available in several countries, such as Korea and Russia, under the trade name Zydena ${ }^{\circledR}$ (Dong-A PharmTech Co, Seoul, South Korea).
SLX-2101 is another PDE5 inhibitor that is being studied. It has shown a strong potency both ex vivo and in vivo. It has a long duration, reaching 36-48 hours, with a safety and tolerability that makes it a candidate for once-daily use. ${ }^{35}$ Its M1 metabolite increases its duration of action even further leading to further benefit for ED patients.

Mirodenafil is a PDE5 inhibitor that has been available in Korea since 2007 as M-vix ${ }^{\circledR}$ (SK Chemicals, Seoul, South Korea). A multicenter, randomized, double-blind, placebocontrolled, parallel-group, fixed-dose study was conducted in Korea and showed the drug to be effective and well tolerated in ED due to several etiologies. ${ }^{36}$

Avanafil is a highly selective PDE5 inhibitor, as discussed later in this review. Several other PDE5 inhibitors have been studied in preclinical trials. FR226807, a nitrobenzamide derivative, inhibits PDE5 isolated from human platelets. ${ }^{37}$ It has, however, the disadvantage of being metabolized to several potential toxic metabolites such as nitroso and hydroxylamine derivatives. T-1032 (an isoquinoline derivative) is a novel, potent, and specific PDE5 inhibitor that has been found to increase cGMP levels in rat vascular smooth muscle cells in a dose-dependent manner. ${ }^{38} \mathrm{KF} 31327$ is more potent than sildenafil as a PDE5 inhibitor, through binding to cGMP noncompetitively. ${ }^{39}$ UK369003 is a PDE5 inhibitor that has been more studied for its effect on lower urinary symptoms than on ED. JNJ-10280205 and JNJ-10287069 are new novel, potent, and selective PDE5 inhibitors that display superior selectivity against PDE1-4 and -6 when compared with sildenafil. In anesthetized dogs, they both exhibit similar efficacy as sildenafil in enhancing erectile function, with no significant effect on cardiovascular parameters. Both compounds are suitable candidates for clinical trials in men with ED. ${ }^{40} \mathrm{NCX}$ 911 has a similar efficacy to sildenafil in causing corporal smooth muscle relaxation; however, since it generates NO it might have a promising role in the future in ED conditions with low NO. ${ }^{41}$

Bremelanotide, a cyclic, heptapeptide melanocortin ana$\log$, is an active metabolite of melanotan-II. ${ }^{42}$ It is erectogenic in men by an action believed to occur at central MC3-Rand MC4-R. ${ }^{43}$ Bremelanotide has been studied in Phase II clinical trials examining its efficacy and safety in variable doses from 0.3 to $10 \mathrm{mg}$. It was found to be effective at doses greater than $1 \mathrm{mg} .{ }^{44}$ In a randomized, double-blind, placebocontrolled study, it was shown to be effective in individuals who have not responded to sildenafil, who cannot tolerate the side effects of PDE5 inhibitors, and in whom sildenafil is contraindicated..$^{45}$ 
The use of topical treatment for ED has always been an interesting one, as it avoids the systemic effects of the treatment. Absorption through the skin and the thick tunica albuginea is an issue of ongoing research. So far, alprostadil has shown some promise as an effective topical agent. In a double-blind, placebo-controlled study, topical gel of 1\% alprostadil (Topiglan ${ }^{\circledR}$, MacroChem Co, Lexington, MA) applied to the glans penis was found to be effective and safe for the treatment of ED, with the main side effect being urogenital pain. ${ }^{46}$

Aviptadil is an injectable formulation of vasoactive intestinal polypeptide in combination with the adrenergic drug phentolamine, which is injected intracavernosally, thus limiting the systemic absorption of the medication. It has been approved in several countries including Denmark and New Zealand and uses autoinjector. This combination was compared with intracavernosal alprostadil in a randomized, open-label, crossover study. Although alprostadil was more effective than the combination, more patients preferred to take the combination because alprostadil was associated with more pain. ${ }^{47}$

Apomorphine is a nonselective dopaminergic agonist that works centrally and has been known for a long time to have erectogenic properties. Initially, the drug was in a sublingual form and was approved in many countries before it was removed from all markets due to its poor efficacy and low patient preference when compared with sildenafil. ${ }^{48}$ VR004 is a novel new inhaled formulation of apomorphine that was examined in two consecutive, randomized, multicenter trials and demonstrated rapid onset of action and reproducible efficacy and safety profiles, making it a possible future first-line therapy for ED. ${ }^{49}$ ABT-724 is a selective dopaminergic D4 agonist that has been shown in rat models to induce erections. It might have a role in the future as a replacement of apomorphine since it bypasses the $\mathrm{D} 2$ receptor, therefore possibly avoiding the nausea that can be associated with apomorphine..$^{50}$

The excitatory amino acid glutamate was found to be a major regulator of erectile function in the central nervous system (CNS) through its hippocampal receptors. These receptors are divided into NMDA (N-methyl D-aspartate), AMPA ( $\alpha$-amino-3-hydroxy-5-methyl-4-isoxazolepropionic acid), and ACPD (1-amino-1,3-dicarboxycyclopentane) receptors. It was shown that by injecting glutamate into each of these receptors in rat models, NMDA was associated with the highest increase in intracavernous pressue (ICP), more than AMPA receptors. ACPD receptors had no statistically significant increase in ICP. This might suggest that NMDA is a future target in ED treatment. ${ }^{51}$
Serotonin exerts a general inhibitory effect on male sexual function, although it can produce an excitatory or inhibitory effect on the erectile function, depending on the action at different sites and different serotonin receptors. ${ }^{52}$ Trazodone, a selective serotonin agonist, has been reported to have a stimulatory effect on erection..$^{53}$ The 5-HT2C receptor was found to be the main serotonin mediator for erection. ${ }^{54} \mathrm{RSD}$ 992, an agonist at 5-HT2C receptors, induces erections and facilitates male copulative behavior, suggesting an important role for the 5-HT2C receptor in the control of erectile mechanisms. ${ }^{52} \mathrm{YM} 348$ is a novel, potent and orally active 5-HT2C receptor agonist that has been found to induce penile erections and hypolocomotion in rats. ${ }^{55}$

BAY41-2272 was synthesized and shown to stimulate soluble guanylate cyclase in a NO-independent manner, without an effect on cGMP breakdown, thus providing an opportunity to treat ED when endogenous NO production is impaired as in diabetics. In comparison to $\mathrm{YC}-1$, another NO-independent soluble cGMP activator, it has been shown to have distinctly higher potency and no phosphodiesterase inhibitory activity. ${ }^{56,57}$

Rho-kinase is known to inhibit myosin light chain (MLC) phosphatase, thus phosphorylating MLC and causing increased level of activated myosin, thereby causing muscle contraction. ${ }^{58}$ Rho-kinase antagonism was found to stimulate penile erection in rat models. ${ }^{59}$ Topical application of Y-27632 (rho-kinase inhibitor) was studied in rats and it was found to induce erection. High doses of the drug cause a reduction of the systemic blood pressure, but when used topically with appropriate doses it might have potential in the future of ED treatment. ${ }^{60}$

Hexarelin analogue peptides stimulate erectile function centrally by acting on the paraventricular nucleus at the hypothalamus and activating oxytocinergic neurotransmission, in a manner similar to apomorphine. ${ }^{61}$ Hexarelin analogue peptides can also stimulate erection when given systematically, although to a lesser degree than when injected directly into the paraventricular nucleus. ${ }^{62,63}$ Human studies are still lacking.

Oxytocin stimulates erection when injected into the lateral cerebral ventricle, the paraventricular nucleus, the hippocampus, or intrathecally in rats. It stimulates erection through induction of $\mathrm{NO},{ }^{64}$ and its effects are androgen dependent. ${ }^{52}$ Currently, research is only limited to animals. ${ }^{65}$

\section{Gene therapy}

Gene therapy represents a very attractive future direction. The defective gene in the corporal tissue can be restored or the mutant gene can be antagonized. The penis is an easier organ 
to inject the gene therapeutic material directly into without having to inject it through the systemic circulation. The tunica albuginea has a slow turnover rate, making the effect of gene therapy last longer. There will be many categories of patients in which gene therapy will be useful, including diabetic, aging, and in hypercholesterolemia. hMaxi-K is the first gene transfer to go through Phase I clinical trial for ED. The results are encouraging as they show a good safety profile. However, efficacy rate cannot be properly evaluated from a Phase I trial with no control group. ${ }^{66}$ Further clinical trials will need to be done.

\section{Regenerative medicine}

Tissue engineering is being studied for its use in reconstructing the penis or treating ED. Kim et al have developed a technique using a sural autologous nerve graft to preserve the continuity of the cavernous nerves during radical prostatectomy, with good results. ${ }^{67}$ Kershen et al presented evidence that human corporal smooth muscle cells used along with biodegradable polymer scaffolds can be used as corporal smooth muscle tissue both in vivo and in vitro. ${ }^{68}$ Falke et al showed that human corporal smooth muscle cells and endothelial cells embedded in a mesh acellular collagen matrix are able to form well vascularized corporal tissue in vivo. ${ }^{69}$ Pilatz et al have described cell isolation protocols and characterized their culture compositions, excluding mainly fibroblasts, in order to develop pure smooth muscle cells, endothelial cells, and fibroblastic cells that are derived from the penis. ${ }^{70}$ Regenerative therapy remains mostly at the basic science level and still needs further research and development.

\section{Avanafil}

As mentioned earlier, there is a need for different medications for ED because the current PDE5 inhibitors do not work for every patient. Therefore, newer PDE5 inhibitors have been developed. One of these new drugs, avanafil, is currently undergoing Phase III clinical trials. Avanafil, an oral medication for the treatment of ED, has been designed to be a fast-acting and highly selective PDE5 inhibitor.

Avanafil (4-[(3-chloro-4-methoxybenzyl)amino]-2-[2(hydroxymethyl)-1-pyrrolidinyl]-N-(2-pyrimidinylmethyl)-5pyrimidinecarboxamide;(S)-2-(2-hydroxymethyl-1pyrrolidinyl)-4-(3-chloro-4-methoxybenzylamino)-5-[(2pyrimidinylmethyl)carbamoyl]pyrimidine) is a pyrimidine derivative that exists as a single enantiomer with $\mathrm{S}$ stereochemistry and has a molecular weight of 483.95 Da. In its pure form it looks as a white crystalline powder that is minimally soluble in water and moderately soluble in organic solvent. It is more soluble in acidic buffer and less soluble in neutral and alkaline buffers. ${ }^{71}$

The enzymatic inhibition of different PDE isoenzymes for avanafil was examined and compared with that of sildenafil. Both avanafil and sildenafil inhibit PDE5 isolated from canine lung in a dose-dependent manner; however, the inhibition of PDE6 and PDE1 was less than PDE5 in avanafil compared to with sildenafil. ${ }^{71}$ Using electroretinogram (ERG) as a method to determine the degree of inhibition of PDE6 in the retina in anesthetized dogs, sildenafil caused a dose-dependent time delay to peak of ERG positive wave, indicating decreased activation of retinal cone cells secondary to increased inhibition of PDE6; whereas avanafil showed that it is unlikely to affect retinal function at pharmacologically appropriate doses. The results were replicated in the awake male and female dogs, further confirming the low likelihood of avanafil affecting retinal function. ${ }^{71}$

In anesthetized dogs, both sildenafil and avanafil potentiated nitroglycerine (NTG)-induced hypotension, but to a lesser degree in avanafil than in sildenafil. Both drugs also potentiated sodium nitroprusside (SNP)-induced inhibition of platelet aggregation but to a lesser extent in avanafil than in sildenafil. In-vitro analysis of human platelet-rich plasma from healthy male volunteers demonstrated that avanafil potentiated the SNP-induced inhibition of platelet aggregation at a concentration of $10 \mu \mathrm{M}$; however, sildenafil had the same effect at concentrations of only $0.1 \mathrm{nM}$ and $1 \mu \mathrm{M} .{ }^{71}$

Studies in rats showed that there is no change in behavior or physical activity at oral doses of $30 \mathrm{mg} / \mathrm{kg}$ and $180 \mathrm{mg} / \mathrm{kg}$ of avanafil when observed for 24 hours. When they were given up to $1000 \mathrm{mg} / \mathrm{kg}$ there was no change in bodyweight. Two hours after $1000 \mathrm{mg} / \mathrm{kg}$ administration, one of six rats demonstrated reduction in spontaneous physical activity, which resolved at 4 hours after administration. Extensive CNS studies in rats did not show a change in sleeping time, spontaneous locomotor activity, acetic acid-induced writhing, or rectal temperature at oral doses of 100 or $300 \mathrm{mg} / \mathrm{kg} .^{71}$

Further tests on conscious dogs showed no change in heart rate (HR), systolic blood pressure (SBP), diastolic blood pressure (DBP), and mean blood pressure (MBP) at avanafil doses up to $10 \mathrm{mg} / \mathrm{kg}$, but at $30 \mathrm{mg} / \mathrm{kg}$ two of four dogs demonstrated a drop of SBP, DBP, and MBP at 1 and 3 hours post-administration, which was accompanied by an $80 \%$ increase in HR. There was no change in respiratory rate or ECG parameters. Both avanafil and sildenafil caused vasodilatory action in rat aorta, but less pronounced with avanafil at $10 \mu \mathrm{M}$. In the gastrointestinal tract, avanafil 
showed a mild inhibition of spontaneous jejunal movement in rabbits and agonist-induced contraction of guinea pig ileum. No effect was seen on gastric emptying or small intestinal transit time in mice, and no effect on gastric juice secretions in rats. In addition, no effect was seen for avanafil on urine output, urinary electrolyte excretion, hematocrit, prothrombin time, activated partial thromboplastin time, plasma fibrinogen concentration, or euglobulin clot lysis time in male rats. ${ }^{71}$

Two studies have looked into the pharmacokinetics of avanafil, with one studying the effect of $200 \mathrm{mg}$ once daily and the other studying the dosing at 12 hour intervals for 7 days, and they demonstrated rapid absorption rate with $\mathrm{T}_{\max }$ of $0.555-0.686$ hours, and $\mathrm{a}_{1 / 2}$ of $1.07-1.23$ hours, without significant accumulation of the drug, whether in once- or twice-daily dosing. The pharmacokinetics parameters were similar after 14 days of daily administration and after single dose ${ }^{72,73}$ (see Table 1). Avanafil is metabolized through the liver cytochrome P450 to 11 metabolites that are less active against PDE5 than the parent compound, with the main route of excretion through the bile for both the oral and the intravenous forms. Thirty-four percent is reabsorbed through the enterohepatic circulation, and it takes 96 hours to eliminate nearly all the drug and its metabolites, with the feces through the bile being the major route of elimination $(>92 \%) .{ }^{71}$ A double-blind, randomized, placebo-controlled, parallel-group, dose-escalation study was conducted at the Asan Medical Center (Seoul, Korea). Subjects were randomly allocated to receive 50, 100, or $200 \mathrm{mg}$ tablets of avanafil or placebo once daily for 7 days. Avanafil was generally well tolerated and had linear pharmacokinetic properties at daily doses of 50-200 mg over 7 days in these healthy Korean male volunteers. ${ }^{74}$

In a Phase II double-blind, randomized, crossover, at-home trial, avanafil was found to have comparable efficacy to sildenafil, as $80 \%$ of the subjects on each product developed erections sufficient for vaginal penetration. ${ }^{75}$ In another Phase II double-blind, crossover clinical trial, avanafil interaction with NTG was studied and compared with sildenafil. Avanafil when taken with NTG caused smaller changes in SBP and HR, a shorter duration of interaction, and fewer subjects with clinically significant hypotension than seen with sildenafil. This suggests that avanafil may be the preferred PDE5 inhibitor of choice in patients that may potentially need to take NTG. ${ }^{76}$ In a multicenter, double-blind, randomized, parallel-design Phase II study, avanafil was found to produce dose-related significant erections sufficient for completion of sexual activity, with a good safety profile in patients with mild to moderate ED. These effects were seen when avanafil was taken 30 minutes before sexual intercourse regardless of food intake. ${ }^{77}$

In a randomized, double-blind, placebo-controlled, Phase III efficacy and safety study that evaluated three doses of avanafil $(50,100$, and $200 \mathrm{mg})$ in 646 men with a history of ED, the participants had dose-dependent increases of $45 \%-64 \%, 46 \%-74 \%$, and $48 \%-77 \%$ success rates for vaginal penetration $(P<0.001$ versus placebo). The rate of successful completion of sexual intercourse increased to $41 \%$ from $13 \%$ in the $50 \mathrm{mg}$ avanafil group and to $57 \%$ from $14 \%$ and $12 \%$ in the 100 and $200 \mathrm{mg}$ groups, respectively $(P<0.001$ versus placebo). Of males who tried to have intercourse within 15 minutes of dosing, 66\%-72\% had successful intercourse compared with $29 \%$ in the placebo group $(P<0.001){ }^{78}$

The data from a 16-week, randomized, double-blind, placebo-controlled Phase III study evaluating two doses of avanafil (100 and $200 \mathrm{mg}$ ) in 390 men with both diabetes and ED, showed that men with both diabetes and ED had similar positive results as men with only ED while taking avanafil, and that more than $60 \%$ of subjects on the $200 \mathrm{mg}$ dose of avanafil had erections sufficient for vaginal penetration. The erections sufficient for penetration increased from $32 \%$ to $54 \%$ with the $100 \mathrm{mg}$ dose, and from $42 \%$ to $63 \%$ with the $200 \mathrm{mg}$ dose, versus an increase of just $36 \%$ to $42 \%$ in the placebo group $(P<0.001)$. Rates of successful intercourse are increased from $8 \%$ to $34 \%$ and from $8 \%$ to $40 \%$ in the 100 and $200 \mathrm{mg}$ groups, respectively, while the placebo group showed an increase of only $10 \%-20 \%(P<0.001){ }^{79}$ There are two other Phase III clinical trials ongoing right now with results still to be published.

The most commonly observed side effects for avanafil in Phase I and II clinical trials were headaches, flushing, nausea, back pain, fatigue, and muscle cramps, with postural hypotension and vasovagal responses at higher doses. In Phase III trial, the most commonly reported side effects are headache, flushing, nasal congestion, nasopharyngitis, sinusitis, and dyspepsia. There were no reports of blue vision, hearing loss, or priapism. ${ }^{78,79}$

\section{Conclusion}

The current three available PDE5 inhibitors (sildenafil, vardenafil, and tadalafil) are considered a first-line treatment for ED and a great advancement in its management. They are preferred by both physicians and patients due to their rapid onset of action, safety profile, and ease of administration. However, there are subsets of patients that do not respond to these PDE5 inhibitors or in whom they are contraindicated. 
Therefore, there is an ongoing need to develop better and safer alternatives.

Avanafil has gone through the three phases of clinical trials, and is still undergoing further Phase III trials. It demonstrates a favorable and unique pharmacokinetic profile with rapid onset of action and short $t_{1 / 2}$ without accumulation of the drug. It has proven to be a safe and effective medication in the treatment of ED. Further research is still lacking to compare avanafil head to head with other PDE5 inhibitors, and to determine the patient groups in which the drug would be most effective, and the patient preference.

As mentioned earlier, there are many future research topics under different stages of development. They range from new forms of PDE5 inhibitors other than avanafil such as (SLX 2101 and mirodenafil), to other forms of pharmacotherapy such as apomorphine and bremelanotide. Topical therapy with alprostadil is also under investigation, while gene therapy and tissue engineering represent an interesting new frontier in ED management.

\section{Disclosure}

The authors report no conflicts of interest in this work.

\section{References}

1. Lue TF, Giuliano F, Montorsi F, et al. Summary of the recommendations on sexual dysfunctions in men. $J$ Sex Med. 2004;1(1):6-23.

2. Wagner G, Fugl-Meyer KS, Fugl-Meyer AR. Impact of erectile dysfunction on quality of life: patient and partner perspectives. Int J Impot Res. Oct 2000;12 Suppl 4:S144-S146.

3. Feldman HA, Goldstein I, Hatzichristou DG, Krane RJ, McKinlay JB. Impotence and its medical and psychosocial correlates: results of the Massachusetts Male Aging Study. J Urol. 1994;151:54-61.

4. Dean RC, Lue TF. Physiology of penile erection and pathophysiology of erectile dysfunction. Urol Clin North Am. Nov 2005;32(4):379-395, v.

5. Lizza EF, Rosen RC. Definition and classification of erectile dysfunction: report of the Nomenclature Committee of the International Society of Impotence Research. Int J Impot Res. 1999;11(3):141-143.

6. Hanash KA. Comparative results of goal oriented therapy for erectile dysfunction. J Urol. 1997;157(6):2135-2138.

7. Montague DK, Jarow JP, Broderick GA, et al. Chapter 1: The management of erectile dysfunction: an AUA update. $J$ Urol. 2005;174(1):230-239.

8. Gupta M, Kovar A, Meibohm B. The clinical pharmacokinetics of phosphodiesterase-5 inhibitors for erectile dysfunction.J Clin Pharmacol. 2005;45(9):987-1003.

9. Nichols DJ, Muirhead GJ, Harness JA. Pharmacokinetics of sildenafil after single oral doses in healthy male subjects: absolute bioavailability, food effects and dose proportionality. Br J Clin Pharmacol. 2002;53: $5 \mathrm{~S}-12 \mathrm{~S}$.

10. Gingell C, Sultana SR, Wulff MB, Gepi-Attee S. Duration of action of sildenafil citrate in men with erectile dysfunction. $J$ Sex Med. 2004;1(2): 179-184.

11. Cheitlin MD, Hutter AM Jr, Brindis RG, et al. Use of sildenafil (Viagra) in patients with cardiovascular disease. Circulation. 1999;99(1): 168-177.

12. Boolell M, Allen MJ, Ballard SA, et al. Sildenafil: an orally active type 5 cyclic GMP-specific phosphodiesterase inhibitor for the treatment of penile erectile dysfunction. Int J Impot Res. 1996;8(2):47-52.
13. Klotz T, Sachse R, Heidrich A, et al. Vardenafil increases penile rigidity and tumescence in erectile dysfunction patients: a RigiScan and pharmacokinetic study. World J Urol. 2001;19(1):32-39.

14. Stark S, Sachse R, Liedl T, et al. Vardenafil increases penile rigidity and tumescence in men with erectile dysfunction after a single oral dose. Eur Urol. 2001;40(2):181-188.

15. Rajagopalan P, Mazzu A, Xia C, Dawkins R, Sundaresan P. Effect of high-fat breakfast and moderate-fat evening meal on the pharmacokinetics of vardenafil, an oral phosphodiesterase- 5 inhibitor for the treatment of erectile dysfunction. J Clin Pharmacol. 2003;43(3):260-267.

16. Gresser U, Gleiter $\mathrm{CH}$. Erectile dysfunction: comparison of efficacy and side effects of the PDE-5 inhibitors sildenafil, vardenafil and tadalafil - review of the literature. Eur J Med Res. 2002;7(10):435-446.

17. Eardley I, Cartledge J. Tadalafil (Cialis) for men with erectile dysfunction. Int J Clin Pract. 2002;56(4):300-304.

18. Brock G. Tadalafil: a new agent for erectile dysfunction. Can J Urol. 2003;10(Suppl 1):17-22.

19. Hellstrom WJG, Overstreet JW, Yu A, et al. Tadalafil has no detrimental effect on human spermatogenesis or reproductive hormones. J Urol. 2003;170(3):887-891.

20. Hatzimouratidis K, Hatzichristou DG. A comparative review of the options for treatment of erectile dysfunction: which treatment for which patient? Drugs. 2005;65(12):1621-1650.

21. Vlachopoulos C, Ioakeimidis N, Rokkas K, Stefanadis C. Cardiovascular effects of phosphodiesterase type 5 inhibitors. J Sex Med. 2009;6(3): 658-674.

22. Kloner RA. Pharmacology and drug interaction effects of the phosphodiesterase 5 inhibitors: focus on alpha-blocker interactions. Am J Cardiol. 2005;96(12B):42M-46M.

23. Hatzimouratidis K, Hatzichristou DG. Looking to the future for erectile dysfunction therapies. Drugs. 2008;68(2):231-250.

24. Wespes E, Amar E, Hatzichristou D, et al. EAU guidelines on erectile dysfunction: an update. Eur Urol. 2006;49(5):806-815.

25. Hatzichristou D. Phosphodiesterase 5 inhibitors and nonarteritic anterior ischemic optic neuropathy (NAION): coincidence or causality? $J$ Sex Med. 2005;2(6):751-758.

26. Linet OI, Ogrinc FG. Efficacy and safety of intracavernosal alprostadil in men with erectile dysfunction. N Engl J Med. 1996;334(14):873-877.

27. Kaplan SA, Reis RB, Kohn IJ, Shabsigh R, Te AE. Combination therapy using oral alpha-blockers and intracavernosal injection in men with erectile dysfunction. Urology. 1998;52(5):739-743.

28. Bennett AH, Carpenter AJ, Barada JH. An improved vasoactive drug combination for a pharmacological erection program. J Urol. 1991; 146(6):1564-1565.

29. Moemen MN, Hamed HA, Kamel II, Shamloul RM, Ghanem HM. Clinical and sonographic assessment of the side effects of intracavernous injection of vasoactive substances. Int J Impot Res. 2004;16(2): 143-145.

30. Shokeir AA, Alserafi MA, Mutabagani H. Intracavernosal versus intraurethral alprostadil: a prospective randomized study. BJU Int. 1999;83(7):812-815.

31. Oakley N, Moore KT. Vacuum devices in erectile dysfunction: indications and efficacy. Br J Urol. 1998;82(5):673-681.

32. Minervini A, Ralph DJ, Pryor JP. Outcome of penile prosthesis implantation for treating erectile dysfunction: experience with 504 procedures. BJU Int. 2006;97(1):129-133.

33. Montague DK, Angermeier KW. Penile prosthesis implantation. Urol Clin North Am. 2001;28(2):355-361, x.

34. Paick J-S, Kim SW, Yang DY, et al. The efficacy and safety of udenafil, a new selective phosphodiesterase type 5 inhibitor, in patients with erectile dysfunction. J Sex Med. 2008;5(4):946-953.

35. Prince W, Campbell AS, Tong W, et al. SLx-2101, a new long-acting PDE5 inhibitor: preliminary safety, tolerability, PK and endothelial function effects in healthy subjects. J Sex Med. 2006;3(Suppl 1):29-30.

36. Paick JS, Ahn TY, Choi HK, et al. Efficacy and safety of mirodenafil, a new oral phosphodiesterase type 5 inhibitor, for treatment of erectile dysfunction. $J$ Sex Med. 2008;5(11):2672-2680. 
37. Hosogai N, Hamada K, Tomita M, et al. FR226807: a potent and selective phosphodiesterase type 5 inhibitor. Eur J Pharmacol. 2001;428(2): 295-302.

38. Takagi M, Mochida H, Noto T, et al. Pharmacological profile of T-1032, a novel specific phosphodiesterase type 5 inhibitor, in isolated rat aorta and rabbit corpus cavernosum. Eur J Pharmacol. 2001;411(1-2):161-168.

39. Hirose R, Okumura H, Yoshimatsu A, et al. KF31327, a new potent and selective inhibitor of cyclic nucleotide phosphodiesterase 5. Eur J Pharmacol. 2001;431(1):17-24.

40. Qiu Y, Bhattacharjee S, Kraft P, et al. JNJ-10280205 and JNJ-10287069: novel PDE5 inhibitors as clinical candidates for erectile dysfunction. Int J Impot Res. 2006;18:477-483.

41. Kalsi JS, Kell PD, Cellek S, Ralph DJ. NCX-911, a novel nitric oxidereleasing PDE5 inhibitor relaxes rabbit corpus cavernosum in the absence of endogenous nitric oxide. Int J Impot Res. 2004;16:195-200.

42. Wessells H, Gralnek D, Dorr R, Hruby VJ, Hadley ME, Levine N. Effect of an alpha-melanocyte stimulating hormone analog on penile erection and sexual desire in men with organic erectile dysfunction. Urology. 2000;56(4):641-646.

43. Molinoff PB, Shadiack AM, Earle D, Diamond LE, Quon CY. PT-141: a melanocortin agonist for the treatment of sexual dysfunction. Ann $N$ Y Acad Sci. 2003;994(1):96-102.

44. Rosen RC, Diamond LE, Earle DC, Shadiack AM, Molinoff PB. Evaluation of the safety, pharmacokinetics and pharmacodynamic effects of subcutaneously administered PT-141, a melanocortin receptor agonist, in healthy male subjects and in patients with an inadequate response to Viagra. Int J Impot Res. 2004;16:135-142.

45. Safarinejad MR, Hosseini SY. Salvage of sildenafil failures with bremelanotide: a randomized, double-blind, placebo controlled study. J Urol. 2008;179(3):1066-1071.

46. Goldstein I, Payton TR, Schechter PJ. A double-blind, placebocontrolled, efficacy and safety study of topical gel formulation of $1 \%$ alprostadil (Topiglan) for the in-office treatment of erectile dysfunction. Urology. 2001;57(2):301-305.

47. Shah PJ, Dinsmore W, Oakes RA, Hackett G. Injection therapy for the treatment of erectile dysfunction: a comparison between alprostadil and a combination of vasoactive intestinal polypeptide and phentolamine mesilate. Curr Med Res Opin. 2007;23(10):2577-2583.

48. Eardley I, Wright P, MacDonagh R, Hole J, Edwards A. An open-label, randomized, flexible-dose, crossover study to assess the comparative efficacy and safety of sildenafil citrate and apomorphine hydrochloride in men with erectile dysfunction. BJU International. 2004;93(9):1271-1275.

49. Riley A, Main M, Morgan F. Inhalation device allows novel administration of apomorphine in men with erectile dysfunction - efficacy and safety findings. J Sex Med. 2010;7(4 Pt 1):1508-1517.

50. Brioni JD, Moreland RB, Cowart M, et al. Activation of dopamine D4 receptors by ABT-724 induces penile erection in rats. Proc Natl Acad Sci U S A. 2004;101(17):6758-6763.

51. Song Y, Rajasekaran M. Effect of excitatory amino acid receptor agonists on penile erection after administration into the CA3 hippocampal region in the rat. Urology. 2004;64(6):1250-1254.

52. Andersson KE. Pharmacology of penile erection. Pharmacol Rev. 2001; 53(3):417-450

53. Lance R, Albo M, Costabile RA, Steers WD. Oral trazodone as empirical therapy for erectile dysfunction: a retrospective review. Urology. 1995;46(1):117-120.

54. Bancila M, Vergé D, Rampin O, et al. 5-Hydroxytryptamine 2C receptors on spinal neurons controlling penile erection in the rat. Neuroscience. 1999;92(4):1523-1537.

55. Kimura Y, Hatanaka K, Naitou Y, et al. Pharmacological profile of YM348, a novel, potent and orally active 5-HT2C receptor agonist. Eur J Pharmacol. 2004;483(1):37-43.

56. Kalsi JS, Rees RW, Hobbs AJ, et al. BAY41-2272, a novel nitric oxide independent soluble guanylate cyclase activator, relaxes human and rabbit corpus cavernosum in vitro. J Urol. 2003;169(2):761-766.
57. Stasch JP, Becker EM, Alonso-Alija C, et al. NO-independent regulatory site on soluble guanylate cyclase. Nature. 2001;410:212-215.

58. Somlyo AP, Somlyo AV. Signal transduction by G-proteins, Rho-kinase and protein phosphatase to smooth muscle and non-muscle myosin II. J Physiol. 2000;522(2):177-185.

59. Chitaley K, Wingard CJ, Clinton Webb R, et al. Antagonism of Rho-kinase stimulates rat penile erection via a nitric oxide-independent pathway. Nat Med. 2001;7:119-122.

60. Dai Y, Chitaley K, Webb RC, Lewis RW, Mills TM. Topical application of a Rho-kinase inhibitor in rats causes penile erection. Int J Impot Res. 2004;16:294-298.

61. Succu S, Mascia MS, Melis T, et al. Pro-VGF-derived peptides induce penile erection in male rats: involvement of paraventricular nitric oxide. Neuropharmacology. 2005;49(7):1017-1025.

62. Melis MR, Succu S, Spano MS, Deghenghi R, Argiolas A. EP 91073 prevents EP 80661-induced penile erection: new evidence for the existence of specific EP peptide receptors mediating penile erection. Neuropharmacology. 2001;41:254-262.

63. Melis MR, Succu S, Spano MS, et al. EP 60761 and EP 50885, two hexarelin analogues, induce penile erection in rats. Eur J Pharmacol. 2000;404(1-2):137-143.

64. Melis MR, Succu S, Argiolas A. Dopamine agonists increase nitric oxide production in the paraventricular nucleus of the hypothalamus: correlation with penile erection and yawning. Eur J Neurosci. 1996; 8(10):2056-2063.

65. Succu S, Sanna F, Melis T, Boi A, Argiolas A, Melis MR. Stimulation of dopamine receptors in the paraventricular nucleus of the hypothalamus of male rats induces penile erection and increases extra-cellular dopamine in the nucleus accumbens: involvement of central oxytocin. Neuropharmacology. 2007;52(3):1034-1043.

66. Melman A, Bar-Chama N, McCullough A, Davies K, Christ G. hMaxi-K gene transfer in males with erectile dysfunction: results of the first human trial. Hum Gene Ther. 2006;17(12):1165-1176.

67. Kim ED, Scardino PT, Hampel ORI, Mills NL, Wheeler TM, Nath RK. Interposition of sural nerve restores function of cavernous nerves resected during radical prostatectomy. J Urol. 1999;161(1): 188-192.

68. Kershen RT, Yoo JJ, Moreland RB, Krane RJ, Atala A. Reconstitution of human corpus cavernosum smooth muscle in vitro and in vivo. Tissue Eng. 2002;8(3):515-524

69. Falke G, Yoo JJ, Kwon TG, Moreland R, Atala A. Formation of corporal tissue architecture in vivo using human cavernosal muscle and endothelial cells seeded on collagen matrices. Tissue Eng. 2003;9(5): 871-879.

70. Pilatz A, Schultheiss D, Gabouev AI, et al. Isolation of primary endothelial and stromal cell cultures of the corpus cavernosum penis for basic research and tissue engineering. Eur Urol. 2005;47(5):710-719.

71. Limin M, Johnsen N, Hellstrom WJG. Avanafil, a new rapid-onset phosphodiesterase 5 inhibitor for the treatment of erectile dysfunction. Expert Opin Investig Drugs. 2010;19(11):1427-1437.

72. Peterson C, Swearingen D. Pharmacokinetics of avanafil, a new PDE5 inhibitor being developed for erectile dysfunction. J Sex Med. 2006;3(Suppl 3):253-254.

73. Lewis RW, Hellstrom W, Gittelman M. Rigiscan evaluation of TA-1790, a novel PDE5 inhibitor for the treatment of men with erectile dysfunction. J Urol. 2006;171(4 Suppl):316.

74. Jung J, Choi S, Cho SH, et al. Tolerability and pharmacokinetics of avanafil, a phosphodiesterase type 5 inhibitor: a single- and multiple-dose, double-blind, randomized, placebo-controlled, dose-escalation study in healthy Korean male volunteers. Clin Ther. 2010;32(6):1178-1187.

75. Results announced for TA-1790 Phase II head-to-head study with Viagra. VIVUS, Inc, press releases March 4, 2004. Available from: http://www.prnewswire.com/news-releases/vivus-announces-resultsfor-ta-1790-in-phase-2-head-to-head-study-with-viagrar-58872542. html. 
76. Nehra A, Swearingen D, Dietrich J, Peterson C. Haemodynamic effects of co-administration of avanafil and glyceryl trinitrate. Eur Urol. 2006;5(2):138.

77. Kaufman J, Dietrich J. Safety and efficacy of avanafil, a new PDE5 inhibitor for treating erectile dysfunction. 2006;5(2):138

78. Goldstein I BC, DiDonato K, et al. Investigating avanafil in the treatment of erectile dysfunction: results of a Phase III, multicenter, randomized, double-blind, placebo controlled clinical trial. AUA Late-Breaking Science Forum 2010, San Francisco, CA; 2010.
79. VIVUS Announces Positive Results From Avanafil Phase 3 Study in Diabetics Presented at the 47th EASD Annual Meeting. 13 September 2011. Available from: http://ir.vivus.com/releasedetail. cfm?ReleaseID $=604819$.

\section{Publish your work in this journal}

Drug Design, Development and Therapy is an international, peerreviewed open-access journal that spans the spectrum of drug design and development through to clinical applications. Clinical outcomes, patient safety, and programs for the development and effective, safe, and sustained use of medicines are a feature of the journal, which has also been accepted for indexing on PubMed Central. The manuscript management system is completely online and includes a very quick and fair peer-review system, which is all easy to use. Visit http://www.dovepress.com/testimonials.php to read real quotes from published authors.

Submit your manuscript here: http://www.dovepress.com/drug-design-development-and-therapy-journal 